\title{
The Dorsal Subiculum Mediates the Acquisition of Conditioned Reinstatement of Cocaine-Seeking
}

\author{
Rémi Martin-Fardon ${ }^{1,3, *}$, Roberto Ciccocioppo ${ }^{2,3}$, Harinder Aujla' and Friedbert Weiss' \\ 'Molecular and Integrative Neurosciences Department, The Scripps Research Institute, La Jolla, CA, USA; ${ }^{2}$ Department of Pharmacological \\ Science and Experimental Medicine, University of Camerino, Camerino, Italy
}

\begin{abstract}
Contextual stimuli present during a single lifetime cocaine self-administration experience acquire occasion-setting actions sufficient to persistently elicit cocaine-seeking behavior in rats, with effects lasting nearly I year. The goal of this study was to identify neural substrates mediating the acquisition of drug-related conditioning taking place during a single cocaine self-administration experience with focus on the subicular formation, a brain site that has been implicated in associative learning relevant for conditioned reward-seeking including conditioned reinstatement. Male Wistar rats were given $2 \mathrm{~h}$ of response-contingent access to intravenous cocaine or saline in the presence of distinct stimuli that served as contextual stimuli associated with the availability and subjective effects of cocaine $\left(\mathrm{S}^{+}\right)$vs saline $\left(S^{-}\right)$. Before onset of the sessions, rats received bilateral microinjections of tetrodotoxin (TTX) into the ventral subiculum (VSUB) or dorsal subiculum (DSUB). Following extinction of responding by withholding cocaine, rats were subjected to reinstatement tests in which exposure to the cocaine- (but not saline) associated stimulus produced strong recovery of responding. This effect was completely abolished in rats with transient TTX inactivation of the DSUB during the conditioning session. TTX inactivation of the VSUB during conditioning did not alter the response-reinstating effects of the cocaine cue. The results suggest that functional integrity of the DSUB, but not VSUB, is critical for the acquisition of conditioned cocaine-seeking controlled by contextual stimuli under conditions where such learning occurs during a single conditioning trial.

Neuropsychopharmacology (2008) 33, I 827- I834; doi: I0. I 038/sj.npp. I30 I589; published online 24 October 2007
\end{abstract}

Keywords: addiction; cocaine; single conditioning; drug cues; drug-seeking behavior; hippocampus

\section{INTRODUCTION}

A major factor contributing to the abuse potential of cocaine is the conditioning of the drug's pharmacological actions with environmental stimuli. Such stimuli can evoke craving and drug desire that may lead to the resumption of cocaine abuse in abstinent individuals (eg O'Brien et al, 1998). Addiction-relevant conditioned effects of drug cues are also well established in the animal literature. In particular, environmental stimuli that have become conditioned to the reinforcing actions of drugs of abuse reliably elicit drug-seeking behavior in animal models of relapse (See, 2002; Shaham et al, 2003; Shalev et al, 2002). Indeed, drug-seeking responses induced by these stimuli show remarkable resistance to extinction with repeated exposure (Ciccocioppo et al, 2001a, b; Weiss et al, 2000, 2001) and, in the case of cocaine, can still be observed after several

\footnotetext{
*Correspondence: Dr R Martin-Fardon, Molecular and Integrative Neurosciences Department, The Scripps Research Institute, SP302120, 10550 North Torrey Pines Road, La Jolla, CA 92037, USA, Tel: + I 858784 7I54, Fax: + I 858784 7|46,

E-mail: rmartinf@scripps.edu

${ }^{3}$ These authors have contributed equally to the work. Received 20 June 2007; revised 23 August 2007; accepted 24 August 2007
}

months of abstinence (Ciccocioppo et al, 2001b; Grimm et al, 2001; Weiss et al, 2001; Lu et al, 2004 for review).

It is generally thought that frequent associations between a substance of abuse and environmental cues are required for these stimuli to acquire conditioned actions that lead to craving or relapse (Ciccocioppo et al, 2001b; Grimm et al, 2001; Meil and See, 1996; O'Brien et al, 1998; O'Brien and McLellan, 1996). For this reason, the persistence of conditioned reinstatement over time has typically been studied in animals with a history of multiple conditioning sessions (eg Ciccocioppo et al, 2001b; de Wit and Stewart, 1981; Grimm et al, 2001; Meil and See, 1996). However, several recent studies have shown that a single conditioning session is sufficient to induce recovery of responding. For example, discrete stimuli paired with cocaine infusions during a single classical conditioning session potently reinstated extinguished lever responding to levels identical to those seen in rats that had experienced daily cocaine-cue pairings (Kruzich et al, 2001; See, 2005). The robustness of conditioned drug-seeking associated with a single conditioning experience has recently been demonstrated by the finding that cocaine-related cues reinstate cocaine-seeking for up to 1 year after one 2 -h conditioning session in rats voluntarily self-administering cocaine (Ciccocioppo et al, 2004). 
The striking persistence of conditioned reinstatement suggests that drug-related learning during an initial cocaine experience may be an important element contributing to continued desire for drug once drug use has begun. Brain regions mediating the acquisition of this behavior are yet to be determined. Therefore, it is important to understand the neural substrates for the acquisition of cocaine-seeking. Neural substrates for the acquisition of conditioned reinstatement have been studied in rats trained to self-administer cocaine and then subjected to a single classical conditioning session (Berglind et al, 2006; Kruzich et al, 2001; See, 2005). In these studies, the basolateral amygdala emerged as an important neural substrate as suggested by the finding that inactivation of this site by the sodium channel blocker tetrodotoxin (TTX) interferes with the acquisition of the conditioned reinforcing effects of discretely drug-paired stimuli (Kruzich et al, 2001; Kruzich and See, 2001).

Another neural substrate of interest for the acquisition of reward-related learning is the hippocampus and its major projection, the subiculum. The hippocampus plays a critical role in establishing representations of spatial context (Matus-Amat et al, 2004; O'Mara, 2005; Phillips and LeDoux, 1992; Sharp, 1997; Sharp and Green, 1994) to guide goal-directed behavior (eg Fanselow, 2000; Frankland et al, 1998). Although a pivotal role of the hippocampus in conditioned responses to fearful stimuli and associative learning relevant for anxiety-related responses is well documented (Anagnostaras et al, 2001; Phillips and LeDoux, $1992,1994)$, the dorsal hippocampus (DH) is also known to have a role in contextual memory retrieval and the occasion-setting action of contextual stimuli (eg Holland and Bouton, 1999). Indeed, the DH has been implicated in the control of ethanol- (Dayas et al, 2007; Zhao et al, 2006) and cocaine-seeking (Franklin and Druhan, 2000; Fuchs et al, 2005; Neisewander et al, 2000) induced by contextual stimuli in reinstatement models. The subiculum, a related brain structure that receives the majority of hippocampal projections (Commins et al, 1998; Stewart, 1997; Witter and Groenewegen, 1990; Young et al, 1997), is hypothetized to participate in mediating associative learning and, thus, likely to play an important role in behavior controlled by environmental stimuli related to drugs of abuse. Theta burst stimulation of the ventral subiculum (VSUB) produces reinstatement of cocaine-seeking after an extinction period (Vorel et al, 2001). Moreover, inactivation of the dorsal subiculum (DSUB) has been shown to reduce cocaineseeking behavior and cocaine self-administration under a second-order schedule of reinforcement (Black et al, 2004). Together these findings suggest that both the VSUB and DSUB participate in mediating the expression of conditioned reinstatement. The question remains, however, what role these regions play in the acquisition of cocaineseeking controlled by the conditioned effects of drug-related contextual stimuli. The purpose of this study was to investigate whether transient inactivation of the VSUB or DSUB interferes with the acquisition of cocaineseeking. This hypothesis was tested by reversibly inactivating the VSUB and DSUB with TTX prior to conditioning in rats during a single 2 -h period of access to intravenous cocaine.

\section{METHODS}

\section{Animals}

Forty male Wistar rats (Charles River, Wilmington, MA; 200-250 g upon arrival), were housed 2-3 per cage in a temperature- and humidity-controlled vivarium on a reverse 12:12 h light/dark cycle with ad libitum access to food and water. All procedures were conducted in strict adherence to the National Institutes of Health Guide for the Care and Use of Laboratory Animals and approved by the Institutional Animal Care and Use Committee of The Scripps Research Institute.

\section{Drugs}

Cocaine hydrochloride (National Institute on Drug Abuse, Bethesda, MD) was dissolved in sterile physiological saline. Cocaine or saline vehicle was intravenously (i.v.) infused at a volume of $0.1 \mathrm{ml}$ over $4 \mathrm{~s}$. TTX (Sigma, St Louis, MO) was dissolved in sterile physiological saline.

\section{Apparatus}

Animals were trained and tested in standard $29 \times 24 \times$ $19.5 \mathrm{~cm}$ operant conditioning chambers (BRS/LVE Inc., Laurel, MD), located inside ventilated sound-attenuating cubicles (BRS/LVE Inc.). All chambers were equipped with two retractable levers $(6 \mathrm{~cm}$ above the grid floor $)$, a white cue light above each lever, and a house light located at the top of the chamber's front panel. Auditory stimuli consisted of a $70 \mathrm{~dB}$ white noise produced by a white noise generator (The Salk Institute, San Diego, CA) presented via an $80 \Omega$ speaker located in the center of the chamber's front panel just below the house light, and an intermittent tone $(7 \mathrm{kHz}$, $70 \mathrm{~dB}$ ), generated by a tone source (Sonalert, Model SC628, 6-28 VDC, Mallory, CO) also positioned in the center of the chamber's front panel just above the speaker. Intravenous infusions were administered by a syringe pump (Razel Scientific Instruments, Stamford, CT) located outside the sound-attenuating boxes. Testing equipment and data collection were controlled by an IBM-compatible computer.

\section{Surgical Procedures}

The rats were prepared with chronic silastic catheters in the right jugular vein under isoflurane (1.0-1.5\%) anesthesia, as described previously (Caine et al, 1993). During the same surgical session, rats were stereotaxically implanted with bilateral stainless steel guide cannulas aimed at the VSUB (AP -5.6; $\mathrm{ML} \pm 4.8 \mathrm{~mm}$ from bregma; and $\mathrm{DV}-5.2 \mathrm{~mm}$ from dura, $N=20$ ), or the DSUB (AP -6.0 ; $\mathrm{ML} \pm 2.8 \mathrm{~mm}$ from bregma and DV $-1.5 \mathrm{~mm}$ from dura, $N=20$ ), according to the atlas of Paxinos and Watson (1998). The guide cannulas were secured with stainless steel screws and dental cement. Following surgery, stylets were inserted and secured to the guide cannulas and remained in place until testing.

\section{Cocaine Self-Administration - Single Conditioning: Effect of TTX}

Before implantation of intravenous catheters, rats were food restricted for 5 days to $85 \%$ of their free feeding weight $(15 \mathrm{~g}$ 
of Purina chow/day). During that time, the rats were trained to lever-press on a fixed ratio one (FR1) schedule for $45 \mathrm{mg}$ food pellet reinforcers (Research Diets, New Brunswick, NJ) to facilitate subsequent acquisition of cocaine-reinforced responding. Once reliable food-reinforced operant responding was established (100 pellets/session in 4-5 days), food was made available ad libitum again. Ten days after recovery from surgery, rats were given access to both intravenous cocaine $(0.25 \mathrm{mg} / 0.1 \mathrm{ml} /$ infusion, infused over $4 \mathrm{~s}$ ) and saline. Immediately before the cocaine session, infusion cannulas (30 gauge) were bilaterally inserted into the guide cannulas with their tips extending $2 \mathrm{~mm}$ (VSUB; final DV: $-7.2 \mathrm{~mm}$ ) or $1 \mathrm{~mm}$ (DSUB; final DV: $-2.5 \mathrm{~mm}$ ) below the guide cannulas. The infusion cannulas were connected to 10- $\mu$ l Hamilton syringes operated by an infusion pump (Harvard Apparatus, Holliston MA). TTX ( $5 \mathrm{ng} / 0.5 \mu \mathrm{l} / \mathrm{side}$ ) or its vehicle (saline) was administered at a flow rate of $0.5 \mu \mathrm{l} / \mathrm{min}$ over $1 \mathrm{~min}$. The cannulas were left in place for $1 \mathrm{~min}$ after the infusion. Animals were then placed into the operant chambers and underwent a single conditioning session identical to that described in Ciccocioppo et al (2004). Briefly, a 2-h cocaine self-administration session was initiated by onset of a $70 \mathrm{~dB}$ white noise that served as a drug-related contextual stimulus $\left(\mathrm{S}^{+}\right)$, followed by extension of the levers into the self-administration chamber. Each response at the right lever resulted in an intravenous infusion of cocaine hydrochloride $(0.25 \mathrm{mg} /$ $0.1 \mathrm{ml}$ ), followed by a 20 -s period (signaled by a white cue light) during which the lever remained inactive to prevent overdosing. All lights were off during cocaine self-administration except after the completion of each ratio requirement, which resulted in the delivery of cocaine. At the end of the session, rats were removed from the operant conditioning chamber for $1 \mathrm{~h}$. Subsequently, a second $2-\mathrm{h}$ conditioning session was conducted during which only saline (non-reward) was available in the presence of a light cue ( $2.8 \mathrm{~W}$ chamber house light) that served as a contextual stimulus associated with non-reward $\left(\mathrm{S}^{-}\right)$. Responses at the right lever produced an intravenous infusion of saline $(0.1 \mathrm{ml})$ followed by inactivation of the lever signaled by a 20-s intermittent tone. Responses at the left (inactive) lever were recorded but had no programmed consequences. After $24 \mathrm{~h}$, responding was extinguished in daily 1 - $\mathrm{h}$ sessions during which both levers were available, but intravenous solutions and the corresponding stimuli were withheld until a criterion of $\leqslant 5$ responses/session for three consecutive days was reached. The two following days, 1-h reinstatement tests began under extinction conditions, but with reintroduction of the contextual stimuli (cocaine $\mathrm{S}^{+}$or nonreward $\mathrm{S}^{-}$) as during the conditioning phase.

To verify the behavioral selectivity of the cocaineassociated cue $\left(\mathrm{S}^{+}\right)$for the conditioned reinstatement tests, on the first day, each rat was randomly tested with either the $\mathrm{S}^{+}$or $\mathrm{S}^{-}$, and on the second day, the order for each rat was reversed. At the end of all testing, rats were killed and their brains were prepared for cresyl violet staining and histological examination of cannula placement. The location of cannula tips was confirmed using a light microscope and mapped onto schematic diagrams (Paxinos and Watson, 1998).

\section{Statistical Analysis}

Differences in responding in the cocaine $v s$ saline selfadministration sessions during the conditioning phase, as well as differences in responding among the extinction and reinstatement phases, were analyzed by two-way mixedfactorial ANOVA, followed by Newman-Keuls post hoc tests.

\section{RESULTS}

\section{Histology}

Diagrams of cannula placements are shown in Figure 1. Only subjects with cannula placements located in the appropriate brain region were included in the data analysis. A total of four rats (two for VSUB and two for DSUB) were excluded from the analysis due to missed injection sites (Figure 1). In addition, rats with non-patent jugular catheters (2 in the DSUB group) following self-administra- a

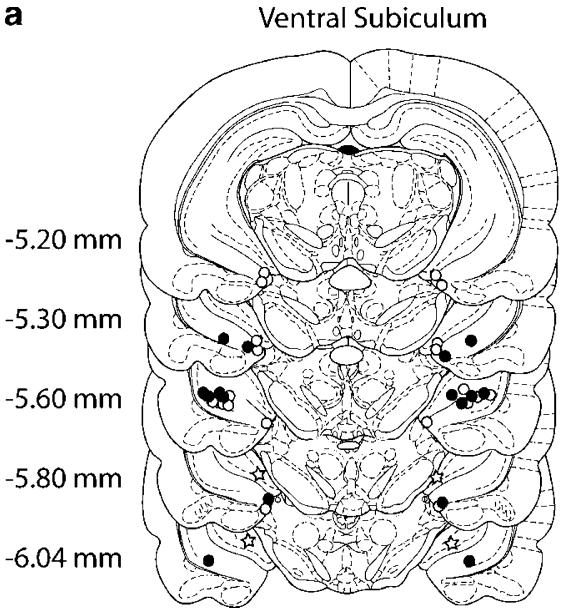

b

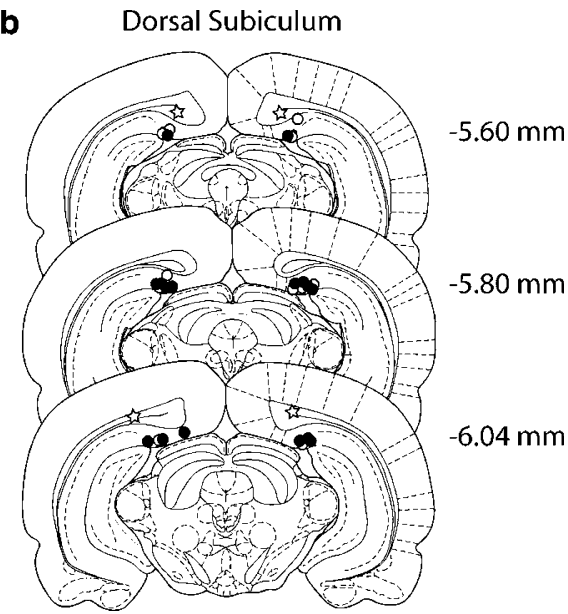

Figure I Cannulas placements for the ventral subiculum (VSUB; a) and dorsal subiculum (DSUB; b). These schematics represent coronal sections of rat brains encompassing the midpoint of placements in the anterior-posterior plane. All drawings are based on the atlas of Paxinos and Watson (I998) with the anterior-posterior coordinates measured from bregma. The marked dots correspond to the injection sites in vehicle (open circle)- and TTX (closed circle)treated animals that were included in the experiment. The open stars correspond to missed injection sites. 


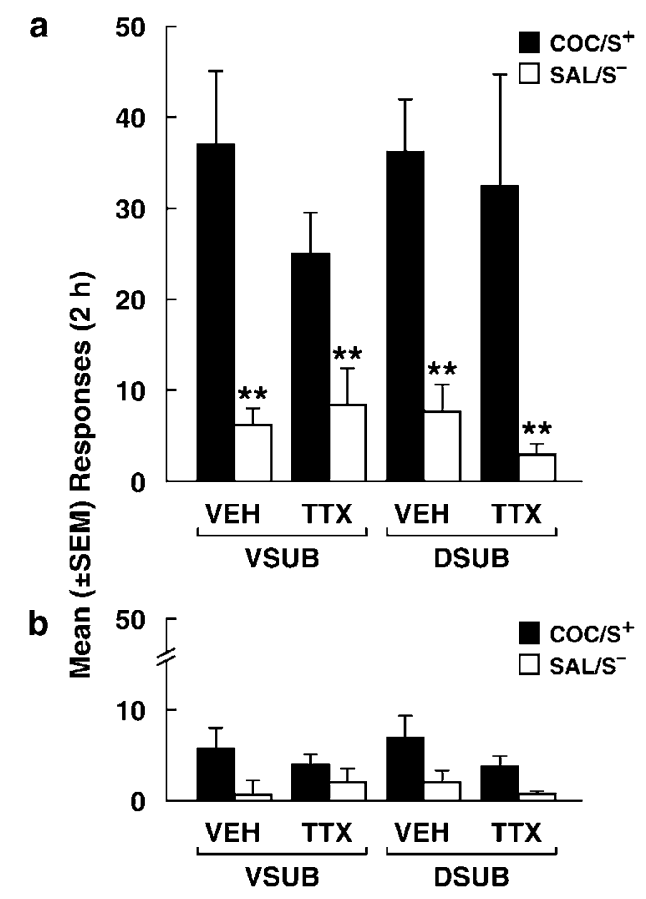

Figure 2 Responses for cocaine $\left(\mathrm{COC} / \mathrm{S}^{+}\right)$and saline $\left(\mathrm{SAL} / \mathrm{S}^{-}\right)$during the single conditioning session following vehicle $(\mathrm{VEH})$ or tetrodotoxin (TTX) inactivation of the ventral subiculum (VSUB) or dorsal subiculum (DSUB) at the active (a) and inactive (b) levers. (a) Responses at the right, active lever, were higher for cocaine compared to saline for both the VSUB and DSUB groups ( ${ }^{*} * 0.0 .0$ I vs respective $\mathrm{COC} / \mathrm{S}^{+}$). (b) Responses at the inactive lever remained low. tion were also excluded from the study. The final number of rats per group was VSUB: $N=18$ (TTX: $N=8$; VEH: $N=10$ ) and DSUB: $N=16$ (TTX: $N=8$; VEH: $N=8$ ).

\section{Conditioning}

Responses during the cocaine self-administration conditioning session were significantly higher than responses emitted during the saline self-administration session $(p<0.01$ vs respective saline, Newman-Keuls following ANOVA; VSUB: $\mathrm{F}_{(1,16)}=21.1 ; p<0.001 ;$ DSUB: $\mathrm{F}_{(1,14)}=$ $17.9 ; p<0.001$; Figure 2a). No differences were noticed in the mean number of cocaine-maintained responses among the groups (ie DSUB vs VSUB and TTX or VEH treatment). Similarly, the number of responses during the saline session did not differ among the four experimental groups (Figure 2a). Responses at the inactive lever remained low throughout the conditioning sessions (Figure 2b). Further scrutiny of the rats' behavior during the self-administration conditioning session (as illustrated in Figure 3) revealed that TTX (administered either in the VSUB or DSUB) did not affect response patterns during self-administration.

\section{Conditioned Reinstatement}

On the first day of extinction, the animals responded an average of $12.8 \pm 2.2$ times at the previously active lever. After initiation of the extinction contigency, the overall mean $( \pm$ SEM) number of days (sessions) to reach the
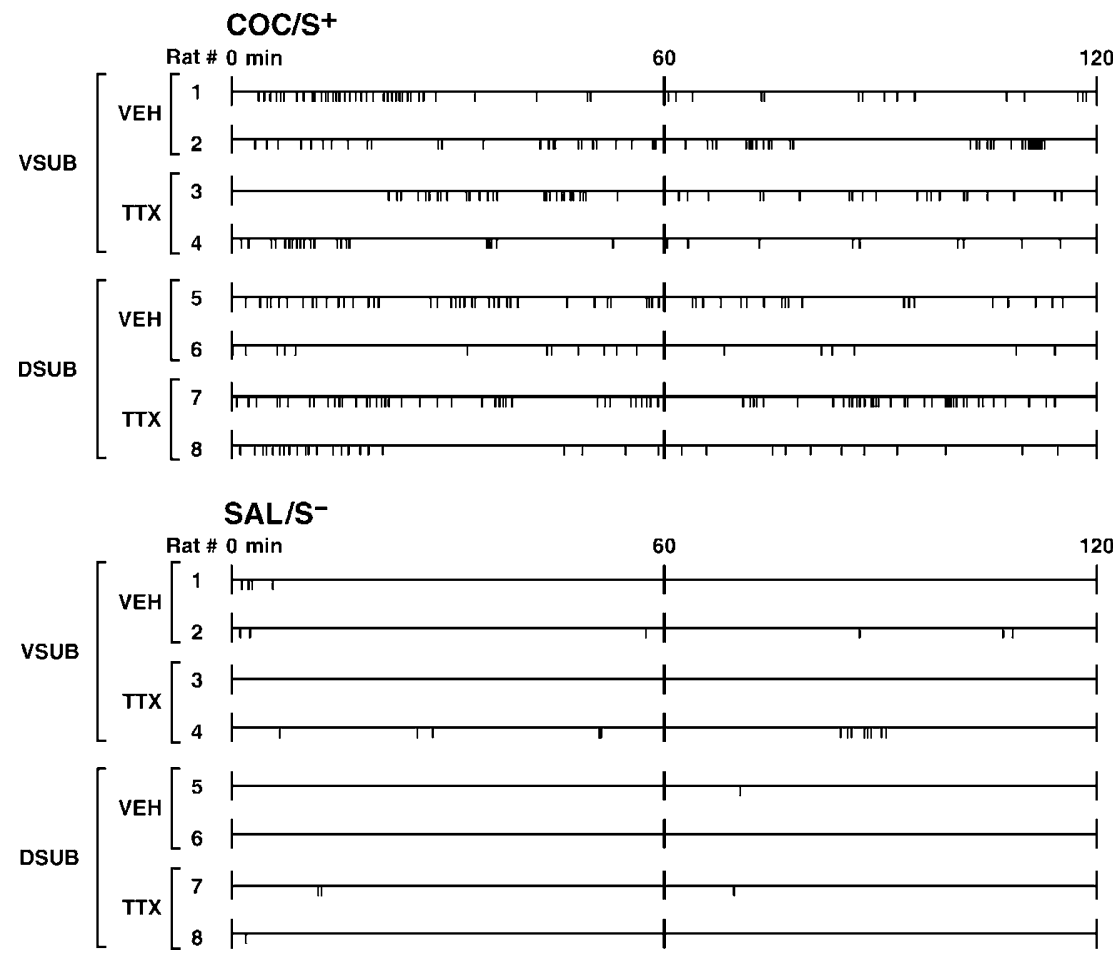

Figure 3 Response patterns during access to cocaine $\left(\mathrm{COC} / \mathrm{S}^{+}\right)$and saline $\left(\mathrm{SAL} / \mathrm{S}^{-}\right)$in animals that received tetrodotoxin (TTX) or its vehicle $(V E H)$ in the ventral subiculum (VSUB) or dorsal subiculum (DSUB) before the onset of the sessions. Lever-press responses are shown as tick marks and are representative of the animals used in the study. No differences were noticeable between behavior emitted by the animals treated with TTX or VEH in the VSUB or DSUB. 
a

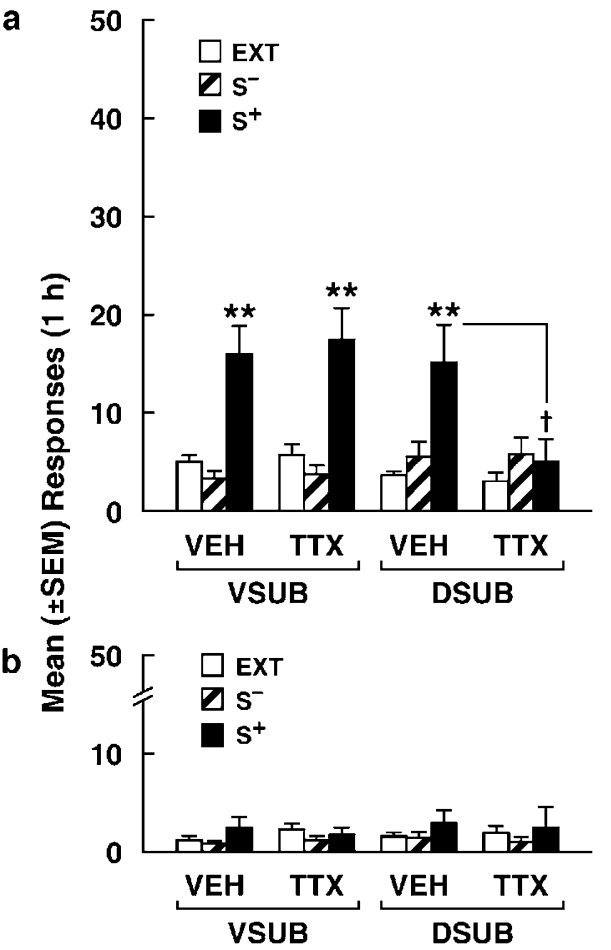

Figure 4 Reinstatement of cocaine-seeking after a single conditioning session in rats that were injected with saline or tetrodotoxin (TTX) in the ventral subiculum (VSUB) or dorsal subiculum (DSUB). (a) Active lever responses: mean number of responses across the last 3 days of extinction (Ext) and responses during subsequent exposure to the stimuli previously paired with cocaine $\left(\mathrm{S}^{+}\right)$vs saline $\left(\mathrm{S}^{-}\right)$availability in rats treated before the single conditioning session in the VSUB or DSUB with vehicle (VEH) or TTX. Newman-Keuls post hoc tests: $*^{*} p<0.01 \mathrm{~S}^{+}$vs extinction or $\mathrm{S}^{-}$in each respective subgroup; ${ }^{\dagger} p<0.05$ vs $\mathrm{VEH}$. (b) Inactive lever responses were negligible.

extinction criterion was $7.1 \pm 0.6$. No difference in the number of extinction sessions necessary to reach the criterion was found among the different groups $\left(\mathrm{F}_{(3,30)}=0.9 p>0.05\right)$. Rats treated with vehicle in the VSUB or DSUB before conditioning resumed responding at the active lever when presented with the $S^{+}$but not the $\mathrm{S}^{-}(p<0.01$, Newman-Keuls following ANOVA; VSUB: $\mathrm{F}_{(2,32)}=28.1 ; \quad p<0.001 ; \quad$ DSUB: $\quad \mathrm{F}_{(2,28)}=7.2 ; \quad p<0.01$; Figure 4a). Rats treated in the VSUB with TTX also resumed responding at the previously active lever when presented with the $S^{+}$but not the $S^{-}(p<0.01$; Figure $4 a)$. In contrast, when administered into the DSUB before conditioning, TTX blocked the reinstating effects of the $S^{+}(p<0.05 v s$ vehicle, Newman-Keuls following ANOVA: main effect for days; $\mathrm{F}_{(2,28)}=7.2 ; p<0.01$, and significant day $\times$ treatment interaction $\mathrm{F}_{(2,28)}=5.1 ; p<0.05$ confirming the inhibitory effect of TTX; Figure 4a). Responses at the inactive lever remained negligible (Figure $4 \mathrm{~b}$ ).

\section{DISCUSSION}

The purpose of this study was to investigate whether transient inactivation of the DSUB or VSUB interferes with the acquisition of conditioned cocaine-seeking. A stimulus $\left(\mathrm{S}^{+}\right)$associated with a single cocaine self-administration experience elicited strong recovery of responding at the previously active lever. Transient inactivation of the DSUB but not VSUB during conditioning abolished the responsereinstating effect of the $\mathrm{S}^{+}$, suggesting that the DSUB participates in the acquisition of conditioned drug-seeking responses.

The results confirm that environmental stimuli paired with a single cocaine experience elicit robust cocaineseeking behavior when subsequently presented without the drug (Ciccocioppo et al, 2004). Thus, a single learning episode is sufficient to establish strong associations between cocaine- and the drug-associated context. This observation is in agreement with earlier findings, which show that a single exposure to cocaine can initiate neurophysiological events in the rat ventral tegmental area closely resembling long-term potentiation (Ungless et al, 2001). Moreover, a single cocaine treatment is sufficient to induce behavioral sensitization and conditioned behavioral sensitization (Guan et al, 1985; Jackson and Nutt, 1993; Ungless et al, 2001), consistent with a role for drug-induced neural plasticity in the motivating effects of drug cues. Similarly, a single treatment with amphetamine or morphine induces long-lasting locomotor sensitization associated with hyperresponsiveness of mesocorticolimbic dopamine and acetylcholine transmission (Robinson et al, 1982; Vanderschuren et al, 1999, 2001). Thus, a single exposure to cocaine produces lasting effects at the behavioral (locomotion), functional (long-term potentiation), and motivational (reinstament) levels.

The hippocampus has a role in developing cognitive representations of contexts during Pavlovian fear conditioning (Fanselow, 2000; Phillips and LeDoux, 1992), in configural learning (Holland and Bouton, 1999; Rudy and Sutherland, 1995), in the acquisition of cocaine-conditioned place preference (Meyers et al, 2003), and in occasion setting (Schmajuk and Buhusi, 1997). The major finding of the present study, that the DSUB plays a selective role in the acquisition of the association between cocaine and the drugrelated context is consistent with literature showing that the hippocampus is a critical substrate for contextual memory (eg Corcoran and Maren, 2001; Holland and Bouton, 1999; Ji and Maren, 2007; Nadel et al, 1985; Phillips and LeDoux, 1992, 1994). Specifically, the failure to observe reinstatement in rats with transient inactivation of the DSUB during the conditioning session suggests that this hippocampal region is critical for the processing of information relevant for the formation of associations between the rewarding effects of cocaine and environmental contexts (represented here by the $S^{+}$) in which the drug-taking experience occurred. The DSUB has also been implicated in creating temporal links between events encoded in the hippocampus (Hampson et al, 2000). One may consequently hypothesize that a loss of DSUB function may have interfered with learning of the temporal contiguity between lever responses and outcome (ie drug reward). In this case, inactivation by TTX should have also interfered with self-administration. However, scrutiny of the pattern of responding during the cocaine self-administration sessions showed no significant difference in the rats' performance among the groups (ie DSUB VEH vs DSUB TTX; Figure 3, $\mathrm{COC} / \mathrm{S}^{+}$). Moreover, following the initiation of extinction training where rats exhibited a relatively high level of responding on the first day, each animal required approximately 7 days to reach the 
extinction criterion. These observations suggest that inactivation of the DSUB did not interfere with the processing of information relevant for the formation of association between responses and their outcome (ie cocaine), but instead impaired the association between the rewarding effects of cocaine and the environmental context.

Inactivation of the VSUB during the conditioning session had no effect on subsequent testing for conditioned reinstatement. This finding is in contrast with earlier studies showing that theta burst stimulation of the VSUB can reinstate cocaine-seeking after an extinction period (Vorel et al, 2001) and that transient inactivation of the VSUB (with lidocaine) blocks reinstatement of cocaineseeking induced by discrete cocaine cues (Sun and Rebec, 2003). Several possibilities may account for this discrepancy. First, it is possible that the VSUB is recruited when conditioning occurs in multiple sessions. In fact, previous studies that demonstrate a role for the VSUB in the expression of cocaine-conditioned reinstatement employed at least 1 week of self-administration to establish stable cocaine self-administration before initiating extinction sessions (Sun and Rebec, 2003; Vorel et al, 2001). Second, while both the DSUB and VSUB have been implicated in the expression of conditioned reinstatement (Black et al, 2004; Sun and Rebec, 2003; Vorel et al, 2001), one may hypothesize that the VSUB is engaged in the expression but not acquisition of conditioned reinstatement. However, although the VSUB is believed to be critical for successful acquisition of spatial information (Floresco et al, 1996), spatial learning is not likely to be critical for performance in the current context (Sun and Rebec, 2003; Vorel et al, 2001). It is, therefore, perhaps not surprising that inactivation of the VSUB during the conditioning session failed to interfere with the development of associations between cocaine and drug-related contextual information, further suggesting that the VSUB may have a role in the expression but not the acquisition of conditioned reinstatement.

The voltage-dependent sodium channel blocker TTX, an agent that temporarily inhibits impulse generation and neural conductance (Narahashi, 1972), has been utilized as a reversible neural inactivating agent in numerous behavioral studies (eg Fuchs et al, 2005, 2006; Grimm and See, 2000; Harlan et al, 1983). In the current study, TTX was not directly administered into the CA1 region of the hippocampus, which would have ruled out a direct role of the CA1 in the acquisition of cocaine-seeking. However, physiological studies have shown that the mean inactivated tissue radius after infusion of $5 \mathrm{ng} / 0.5 \mu \mathrm{l}$ of TTX is $0.7-0.8 \mathrm{~mm}$, and that the maximal effect of TTX at this dose occurs within $2 \mathrm{~h}$ postinfusion and then dissipates exponentially within $24 \mathrm{~h}$ (Lorenzini et al, 1995; Zhuravin and Bures, 1991). Thus, it is unlikely that administration of TTX in the DSUB inactivated the CA1, which is in close proximity to the DSUB. These observations suggest that in the present study the spread of TTX was limited to the brain region of interest.

The disruption of the acquisition of conditioned drugseeking by transient inactivation of the DSUB also is unlikely to be the result of nonspecific effects of TTX. While reversible inactivation of the DH with TTX can impair rat motor coordination as measured in the beam-walking test (Pereira de Vasconcelos et al, 2006), in the present study, TTX microinjections in the DSUB or VSUB did not produce any overt behavioral impairments as can be inferred from the level of operant responding across the experimental groups (Figure 2: vehicle vs TTX injected animals). The failure to observe conditioned reinstatement in rats with transient DSUB inactivation also cannot be explained as merely a consequence of changes in the perception of cocaine effects because TTX did not alter cocaine-reinforced responding during the conditioning session. The absence of nonspecific effects is likely explained by the low dose of TTX, flow rate, and volume of injection compared to the study by Pereira de Vasconcelos et al (2006) and consistent with data showing that selective excitotoxic lesions of the DSUB or the VSUB have no effects on maintenance of cocaine self-administration in rats (Caine et al, 2001).

In summary, the results suggest that functional integrity of the DSUB, but not VSUB, is critical for the acquisition of conditioned cocaine-seeking controlled by contextual stimuli under conditions where such learning occurs during a single conditioning trial. These findings have implications for the transition from initial drug use to addiction and implicate the DSUB as an important neural substrate for the acquisition of drug-related contextual memory, at least during the early stages of this process.

\section{ACKNOWLEDGEMENTS}

This paper is from The Scripps Research Institute and the publication no. of this paper is 18225-MIND from. This research was supported by NIH/NIDA Grants DA07348, DA08467 (FW). We thank ND Stuempfig for technical assistance, M Arends and Dr N Sidhpura for help with the preparation of the manuscript.

\section{DISCLOSURE/CONFLICT OF INTEREST}

The authors have no conflict of interest.

\section{REFERENCES}

Anagnostaras SG, Gale GD, Fanselow MS (2001). Hippocampus and contextual fear conditioning: recent controversies and advances. Hippocampus 11: 8-17.

Berglind WJ, Case JM, Parker MP, Fuchs RA, See RE (2006). Dopamine D1 or D2 receptor antagonism within the basolateral amygdala differentially alters the acquisition of cocaine-cue associations necessary for cue-induced reinstatement of cocaineseeking. Neuroscience 137: 699-706.

Black YD, Green-Jordan K, Eichenbaum HB, Kantak KM (2004). Hippocampal memory system function and the regulation of cocaine self-administration behavior in rats. Behav Brain Res 151: 225-238.

Caine SB, Humby T, Robbins TW, Everitt BJ (2001). Behavioral effects of psychomotor stimulants in rats with dorsal or ventral subiculum lesions: locomotion, cocaine self-administration, and prepulse inhibition of startle. Behav Neurosci 115: 880-894.

Caine SB, Lintz R, Koob GF (1993). Intravenous drug selfadministration techniques in animals. In: Sahgal A (ed) Behavioural Neuroscience: A Practical Approach, vol. 2. IRL Press: Oxford. pp 117-143.

Ciccocioppo R, Angeletti S, Weiss F (2001a). Long-lasting resistance to extinction of response reinstatement induced by ethanol-related stimuli: role of genetic ethanol preference. Alcohol Clin Exp Res 25: 1414-1419. 
Ciccocioppo R, Martin-Fardon R, Weiss F (2004). Stimuli associated with a single cocaine experience elicit long-lasting cocaine-seeking. Nat Neurosci 7: 495-496.

Ciccocioppo R, Sanna PP, Weiss F (2001b). Cocaine-predictive stimulus induces drug-seeking behavior and neural activation in limbic brain regions after multiple months of abstinence: reversal by $\mathrm{D}(1)$ antagonists. Proc Natl Acad Sci USA 98: 1976-1981.

Commins S, Gigg J, Anderson M, O'Mara SM (1998). The projection from hippocampal area CA1 to the subiculum sustains long-term potentiation. NeuroReport 9: 847-850.

Corcoran KA, Maren S (2001). Hippocampal inactivation disrupts contextual retrieval of fear memory after extinction. J Neurosci 21: $1720-1726$.

Dayas CV, Liu X, Simms JA, Weiss F (2007). Distinct patterns of neural activation associated with ethanol seeking: effects of naltrexone. Biol Psychiatry 61: 979-989.

de Wit H, Stewart J (1981). Reinstatement of cocaine-reinforced responding in the rat. Psychopharmacology (Berl) 75: 134-143.

Fanselow MS (2000). Contextual fear, gestalt memories, and the hippocampus. Behav Brain Res 110: 73-81.

Floresco SB, Seamans JK, Phillips AG (1996). Differential effects of lidocaine infusions into the ventral CA1/subiculum or the nucleus accumbens on the acquisition and retention of spatial information. Behav Brain Res 81: 163-171.

Frankland PW, Cestari V, Filipkowski RK, McDonald RJ, Silva AJ (1998). The dorsal hippocampus is essential for context discrimination but not for contextual conditioning. Behav Neurosci 112: 863-874.

Franklin TR, Druhan JP (2000). Expression of Fos-related antigens in the nucleus accumbens and associated regions following exposure to a cocaine-paired environment. Eur J Neurosci 12: 2097-2106.

Fuchs RA, Evans KA, Ledford CC, Parker MP, Case JM, Mehta RH et al (2005). The role of the dorsomedial prefrontal cortex, basolateral amygdala, and dorsal hippocampus in contextual reinstatement of cocaine seeking in rats. Neuropsychopharmacology 30: 296-309.

Fuchs RA, Feltenstein MW, See RE (2006). The role of the basolateral amygdala in stimulus-reward memory and extinction memory consolidation and in subsequent conditioned cued reinstatement of cocaine seeking. Eur J Neurosci 23: 2809-2813.

Grimm JW, Hope BT, Wise RA, Shaham Y (2001). Neuroadaptation: incubation of cocaine craving after withdrawal. Nature 412: 141-142.

Grimm JW, See RE (2000). Dissociation of primary and secondary reward-relevant limbic nuclei in an animal model of relapse. Neuropsychopharmacology 22: 473-479.

Guan LC, Robinson TE, Becker JB (1985). Sensitization of rotational behavior produced by a single exposure to cocaine. Pharmacol Biochem Behav 22: 901-903.

Hampson RE, Hedberg T, Deadwyler SA (2000). Differential information processing by hippocampal and subicular neurons. Ann N Y Acad Sci 911: 151-165.

Harlan RE, Shivers BD, Kow LM, Pfaff DW (1983). Estrogenic maintenance of lordotic responsiveness: requirement for hypothalamic action potentials. Brain Res 268: 67-78.

Holland PC, Bouton ME (1999). Hippocampus and context in classical conditioning. Curr Opin Neurobiol 9: 195-202.

Jackson HC, Nutt DJ (1993). A single preexposure produces sensitization to the locomotor effects of cocaine in mice. Pharmacol Biochem Behav 45: 733-735.

Ji J, Maren S (2007). Hippocampal involvement in contextual modulation of fear extinction. Hippocampus 17: 749-758.

Kruzich PJ, Congleton KM, See RE (2001). Conditioned reinstatement of drug-seeking behavior with a discrete compound stimulus classically conditioned with intravenous cocaine. Behav Neurosci 115: 1086-1092.
Kruzich PJ, See RE (2001). Differential contributions of the basolateral and central amygdala in the acquisition and expression of conditioned relapse to cocaine-seeking behavior. J Neurosci 21: RC155.

Lorenzini CA, Baldi E, Bucherelli C, Tassoni G (1995). Timedependent deficits of rat's memory consolidation induced by tetrodotoxin injections into the caudate-putamen, nucleus accumbens, and globus pallidus. Neurobiol Learn Mem 63: 87-93.

Lu L, Grimm JW, Hope BT, Shaham Y (2004). Incubation of cocaine craving after withdrawal: a review of preclinical data. Neuropharmacology 47(Suppl 1): 214-226.

Matus-Amat P, Higgins EA, Barrientos RM, Rudy JW (2004). The role of the dorsal hippocampus in the acquisition and retrieval of context memory representations. J Neurosci 24: 2431-2439.

Meil WM, See RE (1996). Conditioned cued recovery of responding following prolonged withdrawal from self-administered cocaine in rats: an animal model of relapse. Behav Pharmacol 7: 754-763.

Meyers RA, Zavala AR, Neisewander JL (2003). Dorsal, but not ventral, hippocampal lesions disrupt cocaine place conditioning. NeuroReport 14: 2127-2131.

Nadel L, Willner J, Kurtz E (1985). Cognitive maps and environmental context. In Balsam PD, Tomie A (eds). Context and Learning. Erlbaum: Hillsdale, NJ. pp 385-406.

Narahashi T (1972). Mechanism of action of tetrodotoxin and saxitoxin on excitable membranes. Fed Proc 31: 1124-1132.

Neisewander JL, Baker DA, Fuchs RA, Tran-Nguyen LT, Palmer A, Marshall JF (2000). Fos protein expression and cocaine-seeking behavior in rats after exposure to a cocaine self-administration environment. J Neurosci 20: 798-805.

O'Brien CP, Childress AR, Ehrman R, Robbins SJ (1998). Conditioning factors in drug abuse: can they explain compulsion? J Psychopharmacol 12: 15-22.

O'Brien CP, McLellan AT (1996). Myths about the treatment of addiction. Lancet 347: 237-240.

O'Mara S (2005). The subiculum: what it does, what it might do, and what neuroanatomy has yet to tell us. J Anat 207: 271-282.

Paxinos G, Watson C (1998). The Rat Brain in Stereotaxic Coordinates, 4th edn. Academic Press: San Diego.

Pereira de Vasconcelos A, Klur S, Muller C, Cosquer B, Lopez J, Certa U et al (2006). Reversible inactivation of the dorsal hippocampus by tetrodotoxin or lidocaine: a comparative study on cerebral functional activity and motor coordination in the rat. Neuroscience 141: 1649-1663.

Phillips RG, LeDoux JE (1992). Differential contribution of amygdala and hippocampus to cued and contextual fear conditioning. Behav Neurosci 106: 274-285.

Phillips RG, LeDoux JE (1994). Lesions of the dorsal hippocampal formation interfere with background but not foreground contextual fear conditioning. Learn Mem 1: 34-44.

Robinson TE, Becker JB, Presty SK (1982). Long-term facilitation of amphetamine-induced rotational behavior and striatal dopamine release produced by a single exposure to amphetamine: sex differences. Brain Res 253: 231-241.

Rudy JW, Sutherland RJ (1995). Configural association theory and the hippocampal formation: an appraisal and reconfiguration. Hippocampus 5: 375-389.

Schmajuk NA, Buhusi CV (1997). Stimulus configuration, occasion setting, and the hippocampus. Behav Neurosci 111: 235-257; appendix 258.

See RE (2002). Neural substrates of conditioned-cued relapse to drug-seeking behavior. Pharmacol Biochem Behav 71: 517-529.

See RE (2005). Neural substrates of cocaine-cue associations that trigger relapse. Eur J Pharmacol 526: 140-146.

Shaham Y, Shalev U, Lu L, De Wit H, Stewart J (2003). The reinstatement model of drug relapse: history, methodology and major findings. Psychopharmacology (Berl) 168: 3-20. 
Shalev U, Grimm JW, Shaham Y (2002). Neurobiology of relapse to heroin and cocaine seeking: a review. Pharmacol Rev 54: $1-42$.

Sharp PE (1997). Subicular cells generate similar spatial firing patterns in two geometrically and visually distinctive environments: comparison with hippocampal place cells. Behav Brain Res 85: 71-92.

Sharp PE, Green C (1994). Spatial correlates of firing patterns of single cells in the subiculum of the freely moving rat. $J$ Neurosci 14: $2339-2356$.

Stewart M (1997). Antidromic and orthodromic responses by subicular neurons in rat brain slices. Brain Res 769: 71-85.

Sun W, Rebec GV (2003). Lidocaine inactivation of ventral subiculum attenuates cocaine-seeking behavior in rats. $J$ Neurosci 23: 10258-10264.

Ungless MA, Whistler JL, Malenka RC, Bonci A (2001). Single cocaine exposure in vivo induces long-term potentiation in dopamine neurons. Nature 411: 583-587.

Vanderschuren LJ, De Vries TJ, Wardeh G, Hogenboom FA, Schoffelmeer AN (2001). A single exposure to morphine induces long-lasting behavioural and neurochemical sensitization in rats. Eur J Neurosci 14: 1533-1538.

Vanderschuren LJ, Schmidt ED, De Vries TJ, Van Moorsel CA, Tilders FJ, Schoffelmeer AN (1999). A single exposure to amphetamine is sufficient to induce long-term behavioral, neuroendocrine, and neurochemical sensitization in rats. $J$ Neurosci 19: 9579-9586.
Vorel SR, Liu X, Hayes RJ, Spector JA, Gardner EL (2001). Relapse to cocaine-seeking after hippocampal theta burst stimulation. Science 292: 1175-1178.

Weiss F, Maldonado-Vlaar CS, Parsons LH, Kerr TM, Smith DL, Ben-Shahar O (2000). Control of cocaine-seeking behavior by drug-associated stimuli in rats: Effects on recovery of extinguished operant responding and extracellular dopamine levels in amygdala and nucleus accumbens. Proc Natl Acad Sci USA 97: 4321-4326.

Weiss F, Martin-Fardon R, Ciccocioppo R, Kerr TM, Smith DL, Ben-Shahar O (2001). Enduring resistance to extinction of cocaine-seeking behavior induced by drug-related cues. Neuropsychopharmacology 25: 361-372.

Witter MP, Groenewegen HJ (1990). The subiculum: cytoarchitectonically a simple structure, but hodologically complex. Prog Brain Res 83: 47-58.

Young BJ, Otto T, Fox GD, Eichenbaum H (1997). Memory representation within the parahippocampal region. J Neurosci 17: 5183-5195.

Zhao Y, Dayas CV, Aujla H, Baptista MA, Martin-Fardon R, Weiss F (2006). Activation of group II metabotropic glutamate receptors attenuates both stress and cue-induced ethanolseeking and modulates c-fos expression in the hippocampus and amygdala. J Neurosci 26: 9967-9974.

Zhuravin IA, Bures J (1991). Extent of the tetrodotoxin induced blockade examined by pupillary paralysis elicited by intracerebral injection of the drug. Exp Brain Res 83: 687-690. 